\title{
Eliades Acosta Matos. Un leviatán tropical: las redes clientelares de Trujillo en América Latina y el Caribe.
}

Santo Domingo: Archivo General de la Nación, 2017, 357 pp.

Óscar Gallo*

$\mathrm{E}^{1}$ libro Un leviatán tropical: las redes clientelares de Trujillo en América Latina y el Caribe constituye un desdoblamiento de La telaraña cubana de Trujillo publicada por el historiador Eliades Acosta Matos en 2012. ${ }^{1}$ En ambos casos se destaca el interés por problematizar el estudio de las dictaduras con un enfoque de redes: una apuesta bastante productiva que permite comprender de manera más compleja las relaciones internacionales en el continente. En efecto, en Un leviatán tropical Acosta extiende su análisis a los conflictos, cooperación y relaciones del régimen con otras dictaduras y gobiernos democráticos de la región.

En la historiografia iberoamericana analizar las relaciones internacionales de los regímenes dictatoriales no es una propuesta nueva. Una revisión no exhaustiva permite localizar un interés creciente desde los años ochenta, posterior a la fundación de la revista Relations Internationales (1974) de Jean-Baptiste Duroselle y Jacques Freymond. En este sentido, se puede destacar el análisis sobre los conflictos y cooperación entre Argentina y Brasil o las alianzas entre Franco y Perón. ${ }^{2}$ En la misma línea, sobresalen las reflexiones sobre la propaganda y la acción o las relaciones exteriores del franquismo. ${ }^{3}$

En contraste con el enfoque de redes en el cual se destaca la bidireccionalidad de las relaciones, en el Caribe ha predominado el estudio de formas de cooperación,

* Profesor del Instituto Superior de Formación Docente Salomé Ureña.

1. Eliades Acosta Matos, La telaraña cubana de Trujillo, 2 tomos (Santo Domingo: Archivo General de la Nación, 2018).

2. Helio Jaguaribe, "Brasil-Argentina: breve análisis de las relaciones de conflicto y cooperación", Estudios Internacionales 15.57 (1982): 9-27.

3. Matilde Eiroa San Francisco, "Acción exterior y propaganda. Las visitas de líderes latinoamericanos a Franco", Latinoamérica. Revista de Estudios Latinoamericanos 54 (2012): 111-134; Lorenzo Delgado Gómez-Escalonilla, "Las relaciones internacionales del régimen de Franco: una reflexión”, Arbor 163.642 (1999): 153-178. 
alianza y dependencia con Estados Unidos, ${ }^{4}$ de modo que la agenda internacional de los países de la región está subordinada a la política exterior norteamericana sin indicios de autonomía o resistencia.

Pablo A. Maríñez en un artículo pionero acerca de las relaciones exteriores de la República Dominicana afirma que "fue durante la dictadura de Trujillo cuando [...] se produjo una perfecta articulación entre política interior y política exterior [y] el Estado [asumió] un carácter intervencionista y dinamizador de la economía, en función de los intereses muy particulares de Trujillo". Con otras palabras, la geopolítica se "impuso como mecanismo de sobrevivencia" del régimen. ${ }^{5}$

Nuestro hombre en La Habana de Graham Greene fue publicado en 1958. El año siguiente Carol Reed estrenó, basado en el guion del mismo escritor, una comedia homónima sobre la geopolítica en los tiempos de la Guerra Fría. ${ }^{6}$ Esta sátira del mundo del espionaje relata la historia de Jim Wormold, un vendedor de aspiradoras, que asfixiado por su situación económica acepta convertirse en espía al servicio del gobierno británico. Para cumplir con su labor, Wormold crea una red imaginaria de informantes cuyos cuantiosos sueldos son la recompensa por informar acerca de los planes comunistas en la región. Entre los planes de estos informantes imaginarios se destaca la construcción de una máquina con forma de aspiradora, "inquietante y diabólica", que supera seis veces el tamaño de un hombre.

Pese a que la dictadura de Rafael Leónidas Trujillo (1930-1961) no poseía las mismas motivaciones ideológicas de la Guerra Fría, esa vesania por controlar todo es comparable al leviatán creado por él en el Caribe y América Latina. Como observa Acosta Matos, el tirano dominicano "mantuvo redes secretas y lobbies no solo en los países más cercanos, sino también en algunos tan alejados como Chile, y en otros tan complejos como los mismos Estados Unidos [...] Nada lo detuvo y a ello dedicó millones de dólares, y también la inteligencia y fidelidad de los más lúcidos intelectuales del país" (p. 11). Así, en secreto o con el beneplácito de otros gobiernos igualmente dictatoriales, Trujillo "iluminó" con su mano dura más que su propia isla. ${ }^{8}$

Acosta Matos reflexiona sobre esa especie de "imperialismo dominicano" liderado por Trujillo. De acuerdo con un observador de la época citado por el autor, la paz del Caribe estaba en riesgo dado el carácter intervencionista y militarista del dictador. De hecho, insistía que el interés del trujillato era: "trastornar, cambiar

4. Las relaciones internacionales del régimen cubano merecen un espacio aparte que no es posible analizar en la extensión de esta reseña.

5. Pablo A. Maríñez, "Política exterior de República Dominicana”, Revista Mexicana del Caribe 7.14 (2002): 31 .

6. Carol Reed, “Our Man in Havana”, Reino Unido, 1959.

7. Graham Greene, El décimo hombre (Madrid: Debolsillo, 2013).

8. Nótese la referencia a José Antonio Osorio Lizarazo, Isla Iluminada (Santiago, Republica Dominicana: Editorial el Diario, 1955), una apología del cronista colombiano, que se sumó a otras obras del mismo autor como Así es Trujillo (Buenos Aires: Bartolomé U. Chesino, 1958) y El bacilo de Marx (Ciudad Trujillo: Editorial La Nación, 1959). 
y orientar, con arreglo a su voluntad, la libre determinación de esos pueblos y la subsecuente y actual función de sus gobiernos" (p. 17). Este rechazo a la política del dictador contrastaba con las relaciones amigables y de colaboración regional establecidas con los gobiernos más cercanos "ideológicamente" tales como los de Gerardo Machado, Juan Vicente Gómez, Fulgencio Batista y Marcos Pérez Jiménez. Aunque tal vez sea más preciso afirmar que buscó relacionarse con los gobiernos más afines, pues las dictaduras latinoamericanas se han caracterizado por una endeble y confusa ideología. ${ }^{9}$

Alrededor de los años cincuenta las maniobras de Trujillo para ampliar su red de espionaje en la región se aceleraron hasta alcanzar un nivel de frenesí, como argumenta el autor. Esto concuerda, igualmente, con el creciente recelo del tirano a nivel interno. "El siniestro panóptico" se expandió a medida que se derramaban "cantidades" de dinero en un "servicio de espionaje admirablemente organizado" cuya vigilancia tanto de amigos como enemigos producía informes, denuncias y campañas de desprestigio que saciaban la "voraz paranoia" de Trujillo.

Al mismo tiempo que se consolidaba el servicio internacional de espionaje se fraguaban con papel timbrado las aprobaciones y el respaldo de otros regímenes y gobiernos democráticos. La obsesión de Trujillo no cesó, y, de acuerdo con Acosta Matos, se "realizan campañas a favor del país en el extranjero". Artistas e intelectuales fueron convocados a difundir la gran obra nacional.

Entre las estrategias usadas por Trujillo se destacan su arte para persuadir o ganarse a periodistas extranjeros. Las atenciones y regalos a los invitados al país formaban parte de los dispositivos dirigidos a influir en la opinión pública, sobornar los espíritus e impulsar y fomentar la credibilidad en el régimen, al paso que se desacreditan oponentes y críticos como, por ejemplo, Germán Arciniegas (p. 132), del que se afirmaba era un "comunista y colaborador del más importante y activo de los agentes encubiertos del Kremlin en New York: Jesús de Galíndez” (p. 197).

Las campañas de crédito y descrédito eran lideradas por intelectuales de la región que solidarios, entusiastas, espontáneos o a la expectativa de los beneficios económicos se sumaron con "asombrosa disciplina y armonía al régimen" (p. 165). En esta guerra de papel con sus mercenarios o sicarios de la pluma, como los denomina Acosta Matos, los intelectuales y periodistas utilizaron su retórica para alimentar el apetito del régimen e intentar incidir en la política de los países de la región con la publicación de folletos como el "Manifiesto al pueblo colombiano" de Lucio Pabón, o la difusión de noticias sobre el Bogotazo. A propósito de Colombia, se destaca el vínculo financiero de José Antonio Osorio Lizarazo con Trujillo; al menos tres libros y folletos dedicó a alabar la obra social del régimen trujillista, además de otros panfletos y cartas que escribió mientras estuvo al servicio del tirano.

Ahora bien, el régimen no fue simplemente mediático, también realizó operativos en el terreno apoyado en su red clientelar de más de 20 embajadas, 52 consulados,

9. Allan Angell, "Regímenes dictatoriales desde 1930", Historia general de América Latina, vol. 8, dirs. Marco Palacios y Gregorio Weinberg (Madrid: Ediciones Unesco / Editorial Trotta, 2008) 353-371. 
178 oficinas consulares honorarias; en definitiva, una tupida red de amigos que, en ocasiones, además de espiar, facilitaba asesinatos, secuestros, extorsiones y compra de armas.

Los capítulos finales del libro son de gran interés para los historiadores del mundo del trabajo y los movimientos sociales. Si bien se observa una voracidad similar de controlar todas las redes de relaciones y una lógica de descrédito, es interesante observar la manera como el régimen sorteó la presión de organismos internacionales como la Organización Internacional del Trabajo (OIT) y atendió a las dinámicas de modernización del Estado y a la legislación social acorde con lo que ocurría en otros países de la región. En este sentido, el poder suave consistía en legitimar sus acciones y granjearse la admiración del mundo mediante actividades tan diversas como:

atender reclamos y solicitudes del extranjero; repatriar compatriotas dispersos por el mundo [...] apoyar la lucha en la ONU por el mejoramiento de la condición de las mujeres; aceptar inmigrantes que otros países rechazaban, como judíos, japoneses y republicanos españoles [...] financiar sindicatos en países tan remotos como Chile; promover desde el Estado los intereses de la Iglesia católica y beneficiarla con toda clase de prebendas y privilegios; declararse paladín del anticomunismo y campeón de la hispanidad; intercambiar fastuosos regalos con otros mandatarios; organizar la faraónica Feria de la Paz y la Confraternidad del Mundo Libre, en 1955; promover a escala internacional el merengue dominicano (p. 267).

En una época de álgidos debates internacionales sobre la necesidad de legislar sobre sindicalismo, relaciones laborales y seguridad social, Trujillo habilidosamente extendió sus redes clientelares hasta el país austral al paso que lavó su imagen internacional con la OIT, la Confederación Internacional de Organizaciones Sindicales Libres (CIOSL) y la Federación Estadounidense del Trabajo y Congreso de Organizaciones Industriales (AFL-CIO) mediante invitaciones permanentes al país y una temprana legislación laboral: El Código Trujillo de Trabajo.

En síntesis, con el Caribe y Latinoamérica "cortados y cosidos" ${ }^{10}$ acorde a sus intereses, Trujillo controló y atemorizó opositores internos y externos con un éxito "que ni siquiera lograron los autócratas de los países desarrollados". ${ }^{11}$ Así, en una época en que abundaban las dictaduras, la del "Benefactor" fue precursora tanto en relaciones clientelares como en crueldad e infamia (p. 325). Sin ideologías claras y con un proyecto político moldeado a su conveniencia, la dictadura se extendió durante casi 30 años, entre el 24 de mayo de 1930 y el 30 de mayo de 1961. En el ámbito nacional impulsó la producción y productividad del sector agrario con el propósito de garantizar los recursos necesarios para que el Estado se convirtiera en el motor de la modernización y el cambio social. No en vano el desarrollo de

10. Greene 279.

11. Roberto Cassá, "Hacia una caracterización de la dictadura de Trujillo", Historia general del pueblo dominicano, t. 5, coord. Roberto Cassá (Santo Domingo: Academia Dominicana de la Historia, 2015) 19-56. 
la plantación capitalista y el fortalecimiento de la agricultura de subsistencia en la frontera agraria perviven positivamente en el imaginario rural dominicano. ${ }^{12} \mathrm{Al}$ mismo tiempo que se estimulaban economía y Estado, el régimen devenía en una "dictadura unipersonal" en la cual dinero y poder se concentraban en un único tirano.

DOI: 10.17533/udea.trahs.n16a12

12. Richard L. Turits, Cimientos del despotismo: los campesinos, el régimen de Trujillo y la modernidad en la historia dominicana (Santo Domingo: Academia Dominicana de Historia, 2017); Edwin Croes Hernández, "La depresión económica inicial", Historia general del pueblo dominicano, t. 5, coord. Roberto Cassá (Santo Domingo: Academia Dominicana de la Historia, 2015) 121-202. 